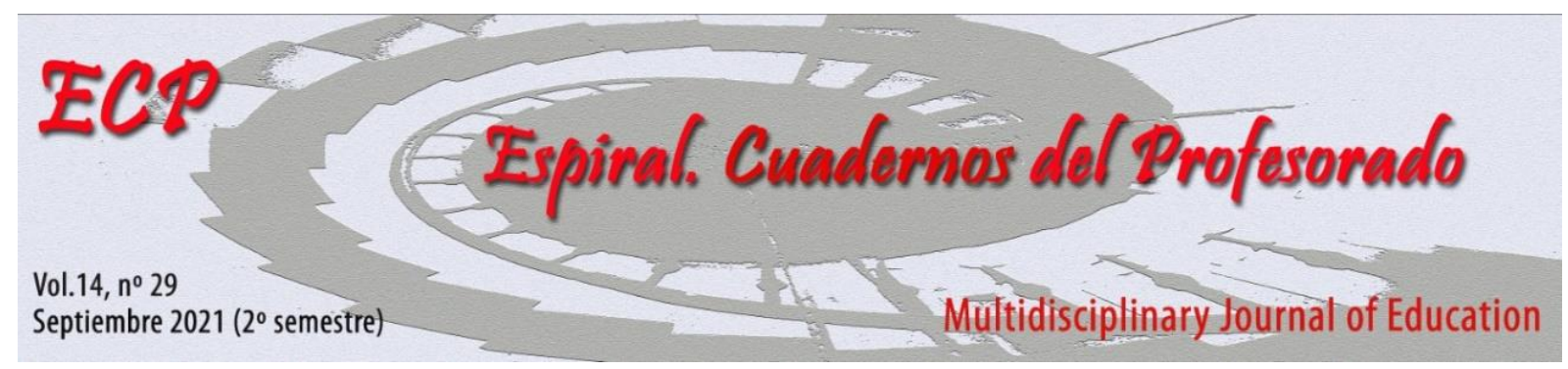

\title{
Escribir y comentar literatura en la red: el caso de la plataforma clubdeescritura.com
}

\section{Writing and commenting on literature online: the case of the clubdeescritura.com platform}

\author{
Moisés Selfa Sastre ${ }^{1}$ y Enric Falguera García ${ }^{1}$ \\ ${ }^{1}$ Universitat de Lleida, España
}

\section{Resumen}

La manera, el modo de publicar y la difusión de las creaciones literarias ha ido evolucionado con los avances tecnológicos relacionados con Internet. El autor y el lector ya no interaccionan solo a través del texto, sino que existen diferentes entornos digitales para que el primero pueda globalizar sus creaciones y el segundo pueda, además de leerlas, comentarlas con el propio escritor u otros usuarios de la red. En este artículo, nos referimos a un entorno digital concreto, clubdeescritura.com, en el que analizaremos dos aspectos principales: en primer lugar, los concursos literarios que esta plataforma digital ofrece a los autores para prestigiar su obra y, en segundo lugar, los comentarios que, en foros de lectura, algunos lectores realizan sobre tres de las obras literarias más comentadas en esta plataforma digital. De este modo, podemos concluir que existe un autor global y un lector también global que, en ocasiones, adopta el rol de escritor para ofrecer comentarios de tipo lingüístico y literario, con los cuales pretende criticar y enjuiciar objetivamente una determinada obra literaria.

Palabras clave: Escritura; lectura; Literatura digital; Foros de lectura.

\begin{abstract}
The way, the manner of publishing and the dissemination of literary creations has evolved with technological advances related to the Internet. The author and the reader no longer interact only through the text, but there are different digital environments so that the first can globalize their creations and the second can, in addition to reading them, comment on them with the writer himself or other users of the network. In this paper, we refer to a specific digital environment, clubdeescritura.com, in which we will analyze two main aspects: firstly, the literary contests that this digital platform offers authors to give prestige to their work and, secondly, the comments that, in reading forums, some readers make about three of the most commented literary creations on this digital platform. In this way, we can conclude that there is a global author and a global reader who, on occasions, adopts the role of writer to offer comments of a linguistic and literary nature, with which they intend to criticize and to judge objectively a certain literary work.
\end{abstract}

Keywords: Writing; Reading; Digital literature; Reading forums.

Fecha de recepción: 27/01/2021

Fecha de aceptación: 14/09/2021

Correspondencia: Moisés Selfa Sastre, Universitat de Lleida, España Email: moises.selfa@udl.cat 


\section{Escritura y lectura en la red: algunas consideraciones importantes en torno a la literatura digital y los foros de lectura}

Hasta hace no muchas décadas, las máquinas de escribir y los cuadernos de escritura eran prácticamente los únicos medios en los que 1@s autor@s escribían las diferentes versiones que de sus obras literarias iban componiendo (Lagneaux, 2017, p. 153). Existía un proceso de creación que podemos denominar individual y que, en ocasiones, si la obra finalmente no era publicada, quedaba reducido a un círculo íntimo de familiares y amigos, que emitían un juicio crítico acerca del texto compartido mayormente en papel.

Con la llegada de Internet, y más tarde de las redes sociales, tanto el escritor (profesional o no) como el crítico literario (profesional o no) modificaron sus roles de actuación (Martos, 2010). La escritura literaria y la crítica literaria supieron aprovechar y abrirse un hueco en los diferentes entornos y plataformas que la red les ofrecía (Azevedo, Selfa, y Balça, 2016; García, 2013). El escritor literario ya no solo podrá publicar su obra en sitios web globalizados, sino que, además, tendrá la posibilidad de acceder al conocimiento de una ingente cantidad de títulos de otr@s escritor@s que publican textos como él y en entornos digitales similares a los utilizados por él. El crítico literario, por su parte, insistimos en que sea profesional o no, ya no solo podrá acceder a textos literarios de un modo tradicional (librerías y bibliotecas, por ejemplo), sino que, como el escritor, tendrá la posibilidad de leer una totalidad de obras, más o menos extensas, que están publicadas en espacios virtuales en los cuales podrá comentarlas (Lagneaux, 2017: 153-156).

Podría afirmarse que los blogs (López y Jarvio, 2018) fueron los primeros sitios web en donde un autor podía volcar sus composiciones literarias. Es también en los blogs donde surgen las primeras comunidades literarias, formadas por autores de textos literarios y por los críticos de estos. En ocasiones, autor y crítico literario convergen. En otras no. Sea como fuere, los blogs tienen una larga tradición como espacios digitales para la publicación de textos literarios y, con el progresivo paso de los años, han ido incorporando nuevas herramientas y funcionalidades para la publicación de distintos tipos de textos. Todo ello hace que podamos hablar de los conceptos de prácticas letradas digitales y de literatura digital no como una literatura que solamente aprovecha las novedades y medios tecnológicos para la publicación de textos, sino como expresión propia del genio creador, capaz de asumir las posibilidades que el presente ofrece a 1@s escritor@s.

Existen diferentes definiciones del concepto de literatura digital (por ejemplo, Romero López, 2011; 2013), pero, de entre todas, queremos destacar una por la amplitud semántica que se otorga a este concepto:

La literatura digital es un tipo de práctica artística por lo general multimedia que evidencia un alto grado de implicación -aunque no exclusiva- del lenguaje verbal con función poética, inscribiéndose marginalmente en la institución literaria a partir de un diálogo más o menos específico con la historia literaria en general y con la literatura tecno-experimental en particular. A diferencia de la literatura asociada al medio libro, es literatura generada en/por/desde/hacia dispositivos electrónicos, actual-mente digitales, es decir, por fuera de medios electrónicos analógicos (la radio, la televisión, el video analógico grabado en cintas magnéticas, por ejemplo). Literatura programada en código binario a través de la creación y uso de diversos software y experimentada en vinculación con interfaces digitales. No es literatura digitalizada, como traslado de textos desde el medio impreso a la pantalla, sino nacida digital y en cuyos procedimientos la creación o utilización del código digital informático es intrínseca (Kozak, 2017: 45-46).

Conviene destacar que la definición de esta autora incide en algunos aspectos que hacen diferente la literatura digital de la literatura impresa. Por ejemplo, la existencia de un código binario es algo propio de la literatura digital. Ahora bien, también existe alguna característica que las asemejan, por ejemplo, la función poética que siempre estará asociada a la creación literaria.

Surge, de este modo, un relato con unas características multimedia que, al menos, cumplen con dos criterios: la comunicación de una creación personal en un entorno en el que existe una experiencia de colectividad (autor@s y receptor@s interrelacionan en un mismo nivel como usuarios de la red y con otros usuarios de la misma) y la ruptura de la linealidad narrativa (Romero López, 2011, pp. 43-45), es decir, el texto literario puede ser enriquecido por una cantidad ingente de enlaces a vídeos, archivos de sonidos o

Espiral. Cuadernos del Profesorado | ISSN 1988-7701 | 2021, 14(29), 31-40 
imágenes que refuerzan y complementan su contenido. Es así como en los espacios y redes sociales de lectura y escritura literaria se convierten en lugares de dinámicas adecuadas de lo que la crítica ha denominado Literatura Digital 2.0 (Rovira, 2015, p. 106).

Las redes sociales y otros espacios de lectura y escritura literarias digitales son entornos digitales que Rovira (2016) denomina verticales. En palabras de este autor, "una red social específica con intereses concretos [...] e invitamos a participar a otras personas, por lo que crea una relación "vertical". (Rovira, 2015 , p. 107). Por tanto, se trata de espacios digitales creados con una finalidad determinada -en este caso, la lectura y la escritura literarias- por un grupo de personas que actúan, en muchas ocasiones, como moderadores de las interacciones entre los usuarios de las mismas.

Una de las grandes aportaciones de Internet a la literatura digital es que esta se convierte en lectura social (Beltrán, 2019), es decir, existe la posibilidad de establecer sinergias a través de los medios que ofrece la red. Lluch (2014) ya se refiere a los foros de Internet sobre textos literarios como espacios en los que jóvenes lectores, aunque no exclusivamente, participan compartiendo sus opiniones sobre diferentes lecturas. Cabe incidir que son normalmente jóvenes los que participan de este tipo de lectura social y, en palabras de Cordón y Gómez Días (2014), lectura colaborativa: "La lectura social o colaborativa es aquella que se desarrolla en plataformas virtuales configurando una comunidad que desarrolla formas de intercambio diversas, compartiendo comentarios, anotaciones, valoraciones, etiquetas y, en algunos casos, libros y lecturas". De este modo, los foros virtuales de lectura literaria son el ejemplo claro de lo que es la lectura social: sus usuarios se registran con la finalidad de pertenecer a una comunidad de lectores, que comentan sus obras preferidas y participan en clubes de lectura y tertulias cuyo nexo de unión son los textos literarios (Rovira, 2015, p. 110).

La participación en foros de lectura con comentarios en torno al texto literario permite referirse a lo que Lluch, Tabernero y Calvo (2015) definieron como epitextos virtuales, es decir, "documentos de múltiples tipos, con las funciones comunicativas de comentar, difundir, modificar y ampliar" (798). Mediante estos epitextos el autor y el lector del texto establecen tertulias de tipo literario que pueden llegar a todos los usuarios de la red, que además se sienten interpelados a participar en ellas. Es en estas condiciones que podemos hablar de crítica literaria digital.

Establecidos estos presupuestos teóricos, en las líneas posteriores vamos a referirnos a un entorno de escritura y lectura literaria en el que se provoca la participación en concursos literarios y en donde autores y lectores comparten reflexiones, que tienen como punto de unión el texto literario. Este entorno digital es clubdeescritura.com.

\section{Objetivos y metodología}

Nuestro trabajo tiene cuatro objetivos concretos que definimos a continuación:

- Mostrar y destacar las características más importantes de un entorno digital concreto en el que aparecen creaciones literarias de todo tipo.

- Analizar algunas de las iniciativas, en forma de concurso literario, que esta plataforma digital propone para promover la escritura literaria.

- Observar algunas de las reacciones de los potenciales escritores a la convocatoria de estos concursos.

- Comentar aportes de tipo lingüístico y literario que los usuarios de clubdeescritura.com realizan a tres de las obras literarias publicadas en este entorno digital y que más comentarios han suscitado.

Definidos los objetivos de nuestro trabajo, la metodología que usaremos para alcanzarlos está basada en los siguientes principios de análisis:

- La selección de la plataforma clubdeescritura.com no es una selección arbitraria, sino que se trata de una opción escogida porque en ella participan tanto como escritores como comentadores de textos literarios, autores nóveles y, en general, no profesionales. Por tanto,

Espiral. Cuadernos del Profesorado | ISSN 1988-7701 | 2021, 14(29), 31-40 
se trata de sujetos que sienten interés por la creación literaria como una afición y no como una profesión.

- El análisis de los datos que se realiza consiste en la interpretación hermenéutica tanto de algunos concursos literarios que convoca la plataforma de estudio como de los comentarios y aportes que realizan los usuarios sobre estos concursos, además de tres de las obras literarias más comentadas en clubdeescritura.com. Por tanto, queremos destacar que se trata de un análisis crítico y reflexivo, basado en interpretaciones personajes objetivas y que pretenden resaltar datos relacionados con la creación de textos literarios (Selfa y Balça, 2020, p. 59).

\section{La plataforma clubdeescritura.com: características y escritura en la red}

La plataforma clubdeescritura,com (https://clubdeescritura.com/) se define a sí misma como un entorno innovador de escritura en la red, fundamentalmente de textos poéticos, que fomenta la lectura y el comentario de textos literarios que en ella se van publicando a diario. En noviembre de 2020, fecha de nuestro estudio, contaba con 129.713 autores y lectores registrados.

Las señas de identidad y la razón de ser de esta plataforma parten de la premisa de que "todos los seres humanos, por el hecho de serlo, son contadores de historias y están dotados para mantener una relación activa y creativa con la poesía y con los diversos lenguajes de expresión artística." (https://clubdeescritura.com/) (Arlandis y Rodríguez, 2021). En este sentido, se invita a los usuarios a que compartan sus escritos, siguiendo directrices de autopublicación definidas por este entorno digital de creación, sin límite de extensión y, si lo desea, integrando fotografías, vídeos y otros recursos innovadores dentro del texto. Por tanto, no solo el texto escrito es el que puede formar parte de la publicación en línea, sino que pueden añadirse otras narrativas visuales relacionadas con la imagen, el audio y las posibilidades que estos aportan al texto escrito.

Además, clubdeescritura.com no solo apuesta por la publicación de textos literarios en línea, sino que, además, ofrece otras posibilidades de escritura en línea, que están relacionadas con el comentario crítico de las obras publicadas, lo cual supone la creación de nuevos hipertextos y nuevas narrativas relacionadas con la obra literaria. Desde este punto de vista, clubdeescritura.com apuesta por "una gran comunidad participativa de decenas de miles de lectores y aficionados a la escritura que se leen y ayudan entre sí con sus comentarios." (https://clubdeescritura.com/).

Para que las publicaciones y los comentarios que de estas se deriven sean lo más ricos posibles desde el punto de vista del uso de la lengua y la expresión de un mensaje literario de calidad, clubdeescritura.com ofrece a sus usuarios talleres de escritura accesibles para todo tipo de público.

\section{Concursos literarios en la red}

Una de las características más importantes del clubdeescritura.com es que no solo permite la autopublicación libre de textos literarios, sino que, además, periódicamente fomenta esta creación a través de concursos literarios con importantes premios. En las líneas siguientes, presentaremos 3 de los últimos premios convocados en los que destacaremos las características más importantes de cada uno de ellos.

El II Concurso de greguerías (https://clubdeescritura.com/convocatoria/ii-concurso-degreguerias-2/), convocado desde el 14 de septiembre hasta el 9 de noviembre de 2020, contaba el día 2 de noviembre con 1027 participaciones. Por tanto, se trata de una cifra elevada en un concurso cuyo premio en metálico es de 500 euros. Cada participante puede presentar un máximo de 4 participaciones y se admiten 4 registros de greguerías:

- Greguerías de texto o con una imagen (una sola fotografía o dibujo) o formando parte del texto (de un máximo de 300 caracteres) o ilustrándolo.

- Imágenes con texto sobreimpreso, donde imagen y texto (greguería) interactúan.

- Foto-greguería: la composición fotográfica se propone ser una greguería por sí sola, sin texto. 
- Vídeo-greguería: audiovisuales de un máximo de 30 segundos de duración que respondan al reto de poder ser consideradas una greguería por sí solos o que ilustren una greguería de texto sobreimpreso o con voz.

Como puede observarse, no solo se propone la escritura lineal, sino que se apuesta por la introducción de elementos multimodales relacionados con la imagen gráfica y la producción de vídeos sonoros.

Lógicamente, dicho concurso despierta expectativas y comentarios entre la comunidad de lectores y escritores de clubdeescritura.com. Dichos comentarios pueden leerse en la página que esta plataforma dedica al concurso y en ellos pueden advertirse reflexiones metaliterarias acerca, en este caso, de lo que es una greguería. Por tanto, podemos entender que, tras estas reflexiones, existe un contexto de creación lingüística relacionado con el hecho literario. Veamos algunos ejemplos:

¡Hola a todos!! Este ejercicio de greguerías se las trae :)... como dice Rogelio: no es fácil (pero si muy entretenido!). Gracias a las observaciones de MIGUEL ANGEL NICOLAS tuve que reconocer que dos de mis propuestas eran más bien aforismos. Reemplace La muerte con Narración quebrada y Los sueños con La hamaca.... Muy agradecida con los comentarios y deleitándome con los aportes tan increíbles que pude leer hasta ahora... los sigo leyendo y guardando. (AW).

En este comentario puede leerse una reflexión de tipo literario sobre el concepto de greguería, que, desde luego, no es lo mismo que un aforismo. Dicha reflexión está motivada por la interacción con otro usuario que realizó en su momento algunas reflexiones sobre lo que son las greguerías.

Otro usuario del concurso, al querer conceptualizar el concepto de greguería, propone en la comunidad de usuarios de clubdeescritura.com dos textos de autores conocidos por él, y somete al juicio de los lectores si son o no greguerías:

¡Hola, compañeros!

Esta convocatoria está siendo muy fértil. Me alegro mucho.

Me gustaría poner dos textos -ignoro si son gregerías- que me han resultado muy sugerentes. Ahí van:

- El día se suicida arrojándose al mar. (Vicente Huidobro).

- La pipa es la maceta de las flores de humo. (Ralph del Valle).

No me digáis que no tienen "miga".

Un abrazo. (AM).

El segundo concurso que queremos comentar es el del IV Premio de poesía in-VERSO, convocado entre el 1 de julio y el 15 de septiembre de 2020: https://clubdeescritura.com/convocatoria/iv-concurso-poesia/ El concurso contó con la presencia de 626 participantes, que podían presentar un solo poema o un conjunto de poemas de unos 200 versos (hasta 2000 palabras). La obra premiada será propuesta para ser publicada en un libro electrónico y en papel en la editorial in-VERSO. Además, los 25 finalistas elegidos por el jurado publicarán su obra en un libro electrónico colectivo.

Entre las obras presentadas, podemos citar aquellas que demuestran una buena técnica de escritura poética, ya que replican estrofas canónicas de la literatura castellana, como el Soneto de un loco enamorado (DD) (https://clubdeescritura.com/convocatoria/iv-concursopoesia/leer/9176880/soneto-de-un-loco-enamorado/, u otras estrofas contemporáneas como el haiku. Es el caso del poema Gotas de sol: "Gotas de sol / sin mojar tierra logran / frentes llorosas." (HP) (https://clubdeescritura.com/convocatoria/iv-concurso-poesia/leer/8034724/la-piel-se-cuartea-haikuno-caigas-en-la-lona-haiku-camino-de-santiago-haiku-gotas-de-sol-ni-contigo-ni-sin-ti/). Además, existen un buen número de composiciones que usan el verso libre, de entre las que destacamos esta por el abundante número de sílabas que presenta:

El mapa del mundo está en mi rostro. Soy geografía desterrada, muda y altiva. / Montañas con fallas, mi columna vertebral dibuja, vertientes en mis venas obstruidas. / Lianas antiguas y nuevas en mi pelo, que antaño era trigal y hoy paja deslucida. / Surcadas grietas abren tajo en mi rostro, dibujando un curioso paisaje de agonía (BL) (https://clubdeescritura.com/convocatoria/iv-concursopoesia/leer/9730821/geografia/). 
El concurso suscita entre los usuarios de clubdeescritura.com intervenciones en la red de todo tipo, entre las que destacan las de tipo literario, como esta de RM en la que comparte un poema que finaliza así: "Y tu voz cantora de las bellas notas, / fueron secuestradas por mis esperanzas, / que esperan que llegues de las lontananzas." En estos versos aparece una palabra dialectal, lontananzas, que el propio poeta aclara su uso: "La palabra LONTANANZA; ya prácticamente en desuso, es un "préstamo" del italiano y que se acuñó para uso exclusivo de la poesía, ya hace un "lontano" tiempo" (https://clubdeescritura.com/convocatoria/iv-concurso-poesia/).

Además, el poema compartido, rico en léxico dialectal, logra despertar la sensibilidad de otros lectores digitales que lo comentan a sí, lo que supone un tipo de escritura hipertextual literaria:

Eres un magnífico poeta. Consigues hacer poesía de temas sencillos con versos de gran belleza. Dominas el lenguaje y el vocabulario de tal forma que combinas las palabras con gran maestría, como el pintor que mezcla los colores y alcanza una variedad cromática de gran hermosura. (PH).

Un tercer concurso literario al que nos vamos a referir es Historias con sabor 4, que contó con 445 participaciones. Este evento fue convocado entre el 17 de julio y el 7 de septiembre de 2020. Las obras presentadas no pueden tener más de 500 palabras. y pueden contener también hasta 5 fotografías y vídeos de un máximo de 3 minutos de duración (alojados en plataformas externas del tipo Youtube o Vimeo).

El ganador de este concurso fue AFPM con el relato La maldita sopa de tomate: https://clubdeescritura.com/convocatoria/historias-con-sabor-4/leer/10174225/la-maldita-sopa-detomate/ A juicio del jurado, compuesto por miembros de Talleres de Escritura Fuentetaja,

El relato funciona con una única escena, con la agonía y muerte del protagonista en una cama de hospital, que se expande y calibra su dramatismo a partir de los recuerdos y alucinaciones del enfermo, que focaliza en dos elementos: la sopa de tomate que tomaba en su infancia y la monja que lo obligaba a comerla. Con una estructura circular que le da al texto una fuerza narrativa notable, sor Teresa y la sopa aparecen al comienzo del relato, como recuerdo, antes de contextualizarlo el narrador, y al final, como alucinación, para acompañar al enfermo en sus últimos momentos, en un gesto, con esa frase final, que tiene inevitablemente algo de irónico. (https://clubdeescritura.com/convocatoria/historias-con-sabor-4/)

Por tanto, se valora de esta creación literaria dos aspectos fundamentales y que son propios de la narración literaria: la estructura narrativa y el uso de un lenguaje irónico para transmitir un mensaje muy determinado.

De los relatos finalista destaca el de María, de AW: https://clubdeescritura.com/convocatoria/historias-con-sabor-4/leer/9827951/maria-5/ En este destaca lo siguiente:

Descripciones brillantes, con una adjetivación cuidadísima, con una sensualidad que se va desplazando de un ámbito a otro con una transición apenas perceptible en el vocabulario: primero María, su cuerpo, luego su modo de comer, descrito con la misma sensualidad con que ha sido descrita ella (https://clubdeescritura.com/convocatoria/historias-con-sabor-4/)

O el de La cocina de mis sueños (https://clubdeescritura.com/convocatoria/historias-con-sabor4/leer/8680236/la-cocina-de-mis-suenos/), de BM, del que destaca

un ejercicio intencionadamente nostálgico: remite, con una carga emotiva clara, a un tiempo que personifican su abuelo y su madre, pero la consistencia le viene al relato de la destreza del narrador para volcar la información gastronómica que lo nutre: exhaustiva, precisa, muy cuidadosa en la descripción del proceso completo, que incluye su presentación en la mesa y la propia comida. Es muy eficaz: tanto que las 3 últimas líneas, tan conclusivas, no hacían falta. (https://clubdeescritura.com/convocatoria/historias-con-sabor-4/)

\section{Comentarios y aportes sobre las obras publicadas}

Un tipo de escritura digital creativa es aquella en el que los lectores de los textos literarios se convierten, a su vez, en escritores y críticos. Sus creaciones, así como los comentarios y aportes sobre estas y que tienen como finalidad otorgar mayor calidad a la obra literaria, son de todo tipo como veremos a continuación. 
Para mostrar la interacción entre el lector y el escritor de un mismo texto literario, hemos seleccionado, a modo de ejemplos, tres de las publicaciones que más comentarios suscitan. Se trata, por tanto, de un criterio meramente de tipo cuantitativo, aunque sí objetivo: pretendemos mostrar algunas de las respuestas, a nuestro juicio más destacadas, que provocan tres relatos muy comentados en clubdeescritura.com

Una historia de amor, de TF, es la obra que mayores comentarios, 90 en total, ha suscitado entre los usuarios de clubdeescritura.com. Se trata de una narración tópica en la que dos protagonistas viven una experiencia de amor que será duradera. Su extensión es de 174 palabras. Por tanto, se trata de un microrrelato en el que destacan los frecuentes epítetos que resaltan las características físicas de los enamorados, "ojos castaños", por ejemplo, así como la intensidad del sentimiento de amor: "cortas palabras", "dura conquista”, entre otros.

El texto despierta comentarios en la red de diversa tipología. En primer lugar, nos referiremos a aportes de tipo lingüístico, en el que los usuarios proponen mejoras en el uso de la lengua del escrito. Veamos uno de interesante, realizado por SAdlC, por la precisión de aportes de tipo lingüístico:

No leí todos los comentarios, pero aquí va mi aporte. Creo que algunas palabras sobran. Mientras más quites, más gana el cuento.

"Cuando ella le conoció" eliminar "a él" porque es obvio.

"Es por ello que choca lo que él sintió" se entiende que es por ella.

"Sus ojos castaños tenían algo que la hacían distinta" lo que sigue "a otra mujer" está de mas.

"...sobre lo bonitas que eran las partes de su cuerpo" se cambia el "las" por el "lo"; eliminar "todas" es redundante.

"Durante año y medio él la buscó desesperadamente" se elimina la coma

"Le escribía poemas buscando su corazón, pero este era de otro" se eliminan palabras que sobran y gana el párrafo

"Pasaban los días, y el cada día estaba más desesperado por conseguirla, hasta que un día logró tocar la tecla correcta" se intercala dos comas

"luchó fervientemente centímetro a centímetro por alcanzar..." se invierten las palabras (sic) (https://clubdeescritura.com/obra/1036906/una-historia-de-amor/)

También encontramos para esta obra comentarios más de tipo literario, en el que se hacen alusión a los recursos literarios usados, si bien no se acaba de especificar cuáles en concreto: "La manera poetica en que se presenta esta historia la hace diferente $\mathrm{Al}$ contarla presenta coloridas imágenes de un vínculo entre enamorados. Lo logra utilizando recursos literarios apropiados (sic) (https://clubdeescritura.com/obra/1036906/una-historia-de-amor/).

La segunda publicación a la que vamos a referirnos es Lo que nunca te dije, con 142833 lecturas y 70 comentarios. Se trata de una carta escrita por JVBFH "para alguien que aún perdura en mi memoria, pero quiero sacar de mi corazón". La carta, estructurada en 5 partes, va acompañada de un enlace a un vídeo de la canción Sleeping with Sirens (https://www.youtube.com/watch?v=hzfHnrXCn9Y\&feature=youtu.be), con lo que letra y música forman una simbiosis adecuada para transmitir un mensaje determinado.

La carta empieza así: "No vengo a hablarte de cómo me ha ido, tampoco a preguntar por tus días pasados. Siento que esta carta es mi terapia y desfogue así que estará llena de todas las cosas que nunca te dije..." (https://clubdeescritura.com/obra/730381/lo-que-nunca-te-dije-2/). Es, por tanto, una declaración de intenciones en toda regla: la escritura literaria es una terapia para ahondar en los sentimientos del escritor.

El texto despierta opiniones de todo tipo. Una de las críticas es la siguiente:

Las historias que describes suenan muy superficiales y me llevan a pensar en un amor infantil, siento que leer los primeros dos renglones de cada capítulo darían el mismo resultado que leerla completa, haz el intento tu mism@ (sic) (https://clubdeescritura.com/obra/730381/lo-que-nunca-te-dije-2/).

Existe, pues, una voluntad de aportar soluciones a una escritura literaria que se considera demasiado sencilla, poco trabajada trivial. 
Otros comentarios van en la misma línea, pero ahondan en cuestiones lingüísticas, como este de VBFB: "Obviamente necesitas editar ese texto, limpiarlo de repeticiones, muletillas y palabras que lo ensucian. Pero es muy valioso escribir como respirando sin parar" (https://clubdeescritura.com/obra/730381/lo-que-nunca-te-dije-2/). La propia autora de la carta contesta este comentario del siguiente modo: "Considero que la conexión es importante cuando uno lee y escribe...” (https://clubdeescritura.com/obra/730381/lo-que-nunca-te-dije-2/), con lo que, de algún modo, justifica la técnica de escritura empleada en su carta, en la que pueden caber, por ejemplo, repeticiones intencionadas.

Microrrelato de terror, de $\mathrm{MB}$, con 624 lecturas y 34 comentarios (https://clubdeescritura.com/obra/2116487/microrrelato-de-terror/), es otra de las publicaciones más valoradas en el entorno de escritura literaria digital al que nos referimos en este trabajo. Es un relato breve acompañado de ilustraciones que otorgan fuerza al texto. Destaca por el uso de oraciones relativamente breves y por el drama explicado: un adulto descubre que su cama es ocupada por un niño difunto al que algún día conoció.

Los comentarios que los lectores de este microrrelato realizaron quieren, sobre todo, destacar cuestiones relacionadas con las propiedades textuales del texto. Así, ME, recalcan "la sencillez con la que escribes y a la vez la tensión narrativa que imprimen esas palabras" (https://clubdeescritura.com/obra/2116487/microrrelato-de-terror/). Por su parte, AP, señala que

Me pareció excelente tu manejo de la escritura y de los tiempos del suspenso. Has caminado en la cornisa con paso seguro. O sea, no has caído en la profusión de detalles para el lector, ni en demasiadas suposiciones. (https://clubdeescritura.com/obra/2116487/microrrelato-de-terror/).

EB se refieren a las características de la prosa especificando que

Es una prosa que avanza sin reclamar atención sobre sí misma; se dedica a ir abriendo puerta tras puerta al entender, con suavidad, llenándote de inquietud, pero sin trucos efectistas. El tránsito hacia el duro final, tan peligroso, se nutre también de ese avance sutil que al final te tiene cogido con un nudo sin que te des cuenta cómo lo hace. Lo he leído cuatro veces seguidas, y sigue persistiendo ese halo de misterio, para una historia que contada de otra forma sería una noticia dolorosa y punto. Eso es lo que marca un excelente relato como el tuyo (https://clubdeescritura.com/obra/2116487/microrrelato-de-terror/).

Finalmente, TM destaca la economía lingüística, es decir, el uso de las palabras justas y exactas para este texto literario, si bien formula dos preguntas al lector con las que quiere aclarar detalles relacionados con la interpretación del texto:

Me encantó el ritmo, la economía de las frases. Excelente detalle: “... se esconde debajo de la cama, manteniéndome despierto, tocando el colchón desde abajo." La descripción del estado posterior a la luz transmite soledad. No entendí por qué no hay médicos o enfermeras si la cama está ocupada por otro paciente. O a qué se refiere "mi lado de la cama" (en una cama de hospital) (https://clubdeescritura.com/obra/2116487/microrrelato-de-terror/).

Dichas preguntas son contestadas por el autor del microrrelato, que reconoce, en algún caso, que debe trabajar más su publicación. Se establece, pues, un diálogo multimodal y recursivo en el que nexo de unión entre autor y receptor es el texto:

El personaje dice que no hay médicos ni enfermeras para presagiar en el lector la muerte del personaje en cierto punto de la trama ("desde aquel pitido"). Solo puede ver a aquellos que estén en la cama, al igual que el niño que anteriormente también le veía en la misma, pero sin poder arrebatársela. Es un lugar de tránsito entre la vida y la muerte en el que la realidad se bifurca dejando ver ambos mundos. Respecto a "mi lado de la cama" en una cama de hospital, supongamos que es una cama un poco más grande de lo normal. Ahí me has pillado un poco. Una muy buena observación, (https://clubdeescritura.com/obra/2116487/microrrelato-de-terror/).

\section{Conclusiones}

La Literatura ha dejado de estar y ser escrita exclusivamente en papel. El canal de transmisión de esta ha ido evolucionando con el paso del tiempo y el avance de las nuevas tecnologías asociadas a Internet (Iribarren, 2016). El escritor de literatura ya no es aquel emisor que para difundir su obra debe contar con el apoyo de editoriales que publican su obra en papel, sino que, en la actualidad, existen canales digitales

Espiral. Cuadernos del Profesorado | ISSN 1988-7701 | 2021, 14(29), 31-40 
muy diversos para compartir un texto literario cualesquiera. La calidad de textos literarios que aparecen publicados en entornos digitales sí que es cierto que puede cuestionarse, pero en este artículo no nos hemos ocupado de esta cuestión, sino más bien de las posibilidades que una plataforma digital en concreto ofrece a escritores profesionales y no profesional para globalizar sus creaciones literarias.

Todo ello nos permite afirmar que la Literatura se ha convertido en un fenómeno global en el que "existe un emisor-creador global y un receptor-lector también global" (Romero López, 2013: 272). El nexo de unión entre ambos es el texto digital literario en línea, que además puedes contener hipertextos multimedia de todo tipo con la finalidad de hacerlo más dinámico e interactivo. De ahí que la literatura digital es especialmente creativa no solo en la calidad del mensaje que transmite, sino en la forma externa en que este mensaje es compartido.

La plataforma clubdeescritura,com (https://clubdeescritura.com/) es uno de los múltiples entornos digitales que permiten la autopublicación de literatura digital en línea. Como hemos visto en este trabajo, las posibilidades de edición de textos que posee son variadas, si bien hemos querido destacar básicamente dos aspectos: los concursos literarios que clubdeeescritura.com ofrece a sus usuarios y los comentarios y aportes que escritores y lectores realizan a las obras publicadas. Los concursos literarios son un modo de estimular la literatura creativa de calidad. Existen unas bases y unos premios que otorgan reconocimiento a la obra ganadora. Por tanto, existe una voluntad de prestigiar la literatura digital. En cuanto a los comentarios que suscitan algunas de las obras publicadas en la plataforma digital objeto de estudio, sí que es cierto que son variados, si bien en este trabajo hemos querido referirnos a aquellos que remiten a cuestiones lingüísticas y literarias para mejorar o simplemente valorar objetivamente una obra.

Desde este punto de vista, conviene resaltar que "las redes sociales de lectura son un espacio en constante desarrollo y con distintas posibilidades de actuación”. (Rovira, 2015: 120). Así, ofrecen al lector formas diversas de relacionarse con la lectura (Martínez Serrano, 2009) a partir de intervenciones de todo tipo en el que el componente multimedia puede jugar un papel determinante.

Contribución de cada Autor: "Conceptualización de los conceptos de Escritura y Lectura en la Red, Moisés Selfa. y Enric Falguera.; objetivos y metodología, Moisés Selfa.; análisis de los resultados, Moisés Selfa.; conclusiones, Moisés Selfa; escritura del manuscrito, Moisés Selfa y Enric Falguera.; escritura, revision y edición, Moisés Selfa y Enric Falguera; supervisión, Moisés Selfa y Enric Falguera”.

Financiación: "Esta investigación fue financiada por el Departament de Recerca i Universitats, Departament de Recerca i Universitats, Agència de Gestió d'Ajuts Universitària i de Recerca, 2020 ARMIF 00020”.

Agradecimientos: Agradecemos a la plataforma clubdeescritura.com el poder acceder a los datos allí publicados.

Conflicto de Intereses: "Los autores declaran que no tienen conflicto de intereses".

\section{Referencias (primer nivel de epígrafes)}

Arlandis, Sergio, \& Rodríguez, Josep M. (2021). Análisis de una propuesta didáctica para trabajar la poesía en un aula de Primaria: leer a Leopoldo de Luis. Álabe, 24. http://doi: 10.15645/Alabe2021.24.9

Azevedo, F., Selfa Sastre, M., \& Balça, Â. (2016). La literatura juvenil publicada en Portugal: de las grandes tiradas comerciales a la interacción en la Web 2.0. Revista chilena de literatura, 94, 103-118. http://dx.doi.org/10.4067/S0718-22952016000300006

Beltrán Llavador, J. (2019). Miradas letradas, letras ad-miradas, una conversación con el mundo social. Álabe, 20, 117. http://dx.doi.org/10.15645/Alabe2019.20.4

García Linares, J. M. (2013). Enseñar literatura en entornos digitales. Álabe, 7, 1-17. http://dx.doi.org/10.15645/Alabe.2013.7.6

Iribarren, T. (2016). Obras poéticas domésticas en Internet: Libertad y creatividad. Álabe, 13, 1-10. http://dx.doi.org/10.15645/Alabe2016.13.8

Lagneaux, M. (2017). La escritura literaria en las redes sociales. Letras, 6, 153-156.

López Acosta, S. A., \& Jarvio Fernández, A. O. (2018). Promoción de la lectura en espacios virtuales: el caso del Portal de Lectores y Lecturas de la Universidad Veracruzana. Álabe, 18, 1-18. http://dx.doi.org/10.15645/Alabe2018.18.3

Lluch, G. (2014). Jóvenes y adolescentes hablan de lectura en la Red. Ocnos. Revista de Lectura, 11, 7-20.

Espiral. Cuadernos del Profesorado | ISSN 1988-7701 | 2021, 14(29), 31-40 
Lluch, G., \& Tabernero, R., \& Calvo, V. (2015). Epitextos virtuales públicos como herramientas para la difusión del libro. El profesional de la información, 24(6), 797-804. https://doi.org/10.18239/ocnos_2014.11.01

Martínez Serrano, B. (2009). Propuesta didáctica para fomentar la lectura y el respeto a la diversidad cultural. Espiral. Cuadernos del Profesorado, 2(4), 48-55. https://doi.org/10.25115/ecp.v2i4.896

Martos Núñez, E. (2010). De la república de las letras a internet.: De la ciudad letrada a la cibercultura y las tecnologías del S. XXI. Álabe, 1, 1-16. http://dx.doi.org/10.15645/Alabe.2010.1.3

Romero López, D. (2011). La literatura digital en español: estado de la cuestión. Revista Texto Digital, 7(1), 38-66. https://doi.org/10.5007/1807-9288.2011v7n1p38

Romero López, D. (2013). De lo analógico a lo hipermedia: vías de entrada a la literatura digital. http://www.cervantesvirtual.com/obra/de-lo-analogico-a-lo-hipermedia-vias-de-entrada-a-la-literaturadigital/

Rovira, J. (2015). Redes sociales de lectura: del libro de caras a la LIJ 2.0. Investigaciones sobre lectura, 3, 106-122. https://doi.org/10.24310/revistaisl.vi3.11084

Rovira, J. (2016). Redes sociales en la universidad: profesionales, académicas y de lectura. Álabe, 13, 1-18. http://dx.doi.org/10.15645/Alabe2016.13.4

Selfa, M., \& Balça, Â. (2020). Educación para la vida I Literatura Infantil en la red: el caso de Davide Cali. Contextos educativos, 25, 55-70. https://doi.org/10.18172/con.4200 